\title{
Estudos Dialetológicos no Paraná: convite a um passeio pela história
}

\author{
Fabiane Cristina ALTINO *
}

Resumo: Este artigo busca inventariar os trabalhos dialetológicos (em suas modalidades) realizados no Estado do Paraná, dando ênfase aos dois atlas linguísticos do Estado - Atlas Lingüístico do Paraná - ALPR, de Aguilera (1994a) e ALPR II, de Altino (2007), este ainda sem publicação. É objetivo deste artigo contribuir com a disseminação dos estudos desenvolvidos na área e ressaltar a importância da Dialetologia para o registro e a análise da língua em uso.

Palavras-chave: Dialetologia; Geolinguística; Atlas Linguístico.

Abstract: This article wants to made an inventory of dialectology (on their modalities) realized in state of Paraná giving emphasis to the two linguistic atlas of the State - Linguistic Atlas of Paraná ALPR, by Aguilera (1994a) and ALPR II, by Altino (2007), this without publication yet. The objective of this article is to contribute to the dissemination of the developed studies on the area and to detach the relevance of Dialectology to the register and analysis of the current language.

Key-word: Dialectology; Geolinguistic; Linguistic Atlas.

\section{Introdução}

A língua portuguesa no Brasil, consensualmente não

* Doutorado em Estudos da Linguagem pela UEL. Docente da Universidade Estadual de Londrina. Contato: fabiane_altino@uol.com.br. 
monolítica, apresenta muitas diferenças dialetais, ${ }^{1}$ a maioria das quais ainda não descritas cientificamente. Essas variedades têm servido para identificar e marcar geográfica e socialmente seus usuários. Em decorrência disso, registram-se várias formas de preconceitos resultantes do valor social que se atribuem aos diferentes modos de falar: é muito comum a observação de que as variedades linguísticas de menor prestígio são inferiores ou erradas. A cultura, antes regional e particular, isolada e com costumes relativamente uniformes e cristalizados, deu lugar à civilização universalista e urbana, com seus novos problemas. As comunidades, agora letradas e em contato constante com o mundo moderno, iniciaram uma era na comunicação humana, mais exigente e formal. A migração, o contato entre as culturas, o menor ou o maior grau de acesso à mídia e à escolaridade, entre outros fatores, contribuem para que a língua seja cada vez mais dinâmica e sofra mudanças continuamente.

Essas mudanças, porém, não se fazem de forma homogênea. Há comunidades em que, por diversas razões (culturais, geográficas, por exemplo), a mudança se faz mais lentamente, perpetuando hábitos linguísticos há muito deixados para trás por outras comunidades de fala.

Buscar as diferenciações regionais, verificando as características sócio-históricas que cada comunidade apresenta, e averiguar se elas se refletem nas diversidades geográficas, na busca do retrato linguístico, são metas que devem nortear a tarefa de um dialetólogo. Esses objetivos devem estar presentes não só nos atlas nacionais, mas também nos regionais, por possibilitarem um estudo

\footnotetext{
${ }^{1}$ Para o conceito de dialeto, adotou-se para este trabalho a definição de Alvar (1996, p. 13), para quem dialeto é "un sistema de signos desgajado de una lengua común, viva o desaparecida; normalmente, con una concreta limitación geográfica, pero sin uma fuerte diferenciación frente a otros de origen común. De modo secundario, pueden llamarse dialectos las estructuras lingüísticas, simultáneas a otras, que no alcanzan la categoría de lengua”. Cf., também, Chambers e Trudgill (1994).
} 
da língua mais profundo, por meio de um inventário linguístico, no qual se espelhem algumas mudanças sociais, oferecendo, assim, subsídios para a constituição de um quadro sinótico da história da língua.

Esse anseio de mapear os falares regionais motivou a criação de um núcleo de estudos dialetológicos no Paraná, hoje consolidado e que vem desenvolvendo trabalhos, sobretudo através do método geolinguístico, em um esforço para registrar a fala paranaense. Um pouco da história dos estudos nesta área é o que se pretende contar aqui.

\section{Uma viagem no tempo: um pouco da história da Dialetologia} nacional

Há muito, no Brasil, estudiosos da linguagem vêm pregando a necessidade de estudos dos falares ${ }^{2}$ nacionais. Esse propósito já era discutido em 1920 por Amadeu Amaral (1976, p. 2):

Seria de se desejar que muitos observadores imparciais, pacientes e metódicos se dedicassem a recolher elementos em cada uma dessas regiões, limitando-se estritamente ao terreno conhecido e banindo por completo tudo quanto fosse hipotético, incerto, não verificado pessoalmente. Teríamos assim um grande número de pequenas contribuições, restritas em volume e em pretensão, mas que

\footnotetext{
2 Para o termo falares, adotou-se o conceito fornecido por Câmara Jr. (1981, p. 115): "línguas de pequenas regiões, através de um território lingüístico dado, que se distinguem umas das outras por oposições superficiais dentro do sistema geral de oposições fundamentais que reúne todas numa língua comum. [...] Os falares caracterizam-se ainda, em face da língua comum, pela circunstância de pertencerem à língua cotidiana oral, de sorte que a língua escrita, na pequena região em que vigora, se cria na base da língua comum, embora possa se apresentar às vezes menos ou mais contaminada pelos traços do falar local".
} 
na sua simplicidade modesta, escorreita e séria prestariam muito maior serviço do que certos trabalhos mais ou menos vastos que, de quando em quando, se nos deparam repositórios incongruentes de fatos recolhidos a todo preço e de generalizações e filiações quase sempre apressadas.

Essa preocupação com os falares brasileiros também é preconizada por Houaiss (1960) quando relata sobre a criação do Centro Latino-Americano de Pesquisa de Ciências Sociais, no Rio de Janeiro, em 1957. Assinala a necessidade de o recém fundado centro levar em consideração os aspectos fundamentais do problema linguístico brasileiro, uma vez que

O estudo científico do instrumento de comunicação - no nosso caso concreto, a língua portuguesa afeiçoada às nossas características nacionais - está cada vez mais na dependência de pesquisas de campo, graças às quais se poderá levar a bom termo, num futuro que esperamos não seja remoto, o Atlas Lingüístico do Brasil, melhor, o Atlas Dialectológico Brasileiro. (HOUAISS, 1960, p. 40)

Anteriormente a esse acontecimento, no Congresso Internacional de Lingüística, em Haia, 1928, reiterou-se a necessidade de desenvolver estudos dialetológicos no Brasil, solicitando junto ao governo federal, o patrocínio dos trabalhos necessários ao Atlas Linguístico do Brasil. ${ }^{3}$

Esta idéia ganha corpo com Silva Neto e Cunha, no II Colóquio Internacional de Estudos Luso-Brasileiros, realizado em Lisboa em 1957, que igualmente afirmavam a urgência de estudos dialetológicos pelo método geolinguístico, ressaltando a importância da elaboração de atlas regionais que pudessem investigar, mais detidamente, as variantes de cada região do Brasil.

\footnotetext{
${ }^{3}$ Com vistas, também, ao estabelecimento do Atlas Linguístico do Mundo. Cf. Houaiss (1960, p. 45).
} 
Soma-se a esses pesquisadores Nascentes, cujas proposições estão registradas na publicação das Bases para a elaboração do atlas lingüístico do Brasil (1958, 1961), obras que fornecem as diretrizes gerais para o estabelecimento da rede de pontos, o perfil dos informantes e a elaboração do instrumento de coleta de dados.

Junto com a idéia de um atlas nacional, os pesquisadores ressaltam a importância dos atlas regionais que reside na exaustão com que os dados coletados são trabalhados, fornecendo, além de uma visão panorâmica da língua, a possibilidade de fazer seu inventário e documentar o grau de aculturação presente no espaço geográfico, de realizar o estudo da formação da língua e da sua história. Além disso, podem oferecer materiais agrupados em esferas semânticas e mostrar a distribuição geográfica das palavras. Houaiss (1960, p. 62) sinaliza para a importância dos atlas linguísticos:

As razões determinantes da necessidade de que cada comunidade lingüística possa ter sua fisionomia caracterizada exaustivamente são de várias naturezas. A técnica de apreensão dessa fisionomia lingüística é chamada dialetologia, cujos resultados só se tornam válidos se expostos em forma de atlas. $\mathrm{O}$ atlas lingüístico de uma comunidade lingüística é, por conseguinte, aquele registro mercê do qual todos os aspectos e particularidades dessa comunidade lingüística possam ser descritos, sistematizados, analisados.

Assim, começaram a ser desenvolvidas pesquisas dialetais que buscavam as realidades regionais, elaborando atlas que demonstrassem de forma concreta as possíveis diferenças. $O$ primeiro deles foi o Atlas Prévio dos Falares Baianos - APFB (ROSSI et al., 1963), seguido pelo Esboģo de um Atlas Lingüístico de Minas Gerais - EALMG (RIBEIRO et al., 1977), do Atlas Lingüistico da Paraíba - ALPB (ARAGÃO; MENEZES, 1984), do Atlas Lingüistico de Sergipe - ALS (FERREIRA et al., 1987), do Atlas Lingüístico do Paraná-ALPR (AGUILERA, 1994a), o Atlas Lingïistico-Etnográfico 
da Região Sul do Brasil - ALERS (KOCH et al., 2002) e o Atlas Lingüistico de Sergipe - ALS II (CARDOSO, 2005), Atlas Geosociolingüistico do Pará - ALISPA (RAZKY, 2004) e, recentemente, o Atlas Lingüistico de Mato Grosso do Sul-ALMS (OLIVEIRA, 2007).

\section{A história do Paraná nos estudos dialetais}

O Paraná, com seu atlas publicado em 1994, é um dos estados pioneiros na investigação dos dialetos. $\mathrm{O}$ estudo sobre o português falado neste Estado pode ser dividido em duas fases. Uma delas abrange o final do século XIX até a década de 40 do século XX. Apesar de importantes para o conhecimento das características linguísticas, essas coletâneas não tinham como objetivo principal descrever a fala paranaense e, por conseguinte, apresentam poucos dados para um estudo mais acurado da língua. A outra fase se inicia na década de 50 do século passado e chega aos nossos dias.

As primeiras informações sobre os falares paranaenses remontam ao século XIX, quando o pesquisador francês Auguste de Saint-Hilare (1978), em anotações de suas viagens às províncias brasileiras entre os anos de 1816 e 1822, comenta sobre o falar paranaense, sobretudo no campo fonético. Suas observações sobre a linguagem utilizada no Paraná do século XIX são poucas, mas consideradas de relevância para conhecer traços dos falares da época.

O livro de memórias de José Correia Coelho, publicado em 1844, relata suas viagens pelo Paraná e, em duas passagens, relata sobre um falar pontuado por interjeições e usos de hipérboles, conforme registra Mercer (1992, p. 28).

Foi a partir do trabalho do General José Cândido da Silva Muricy, apresentado por Andrade Muricy durante o Primeiro Congresso da Língua Nacional Cantada no Rio de Janeiro (1938), que o estudo do léxico paranaense passou a tomar corpo. Segundo Andrade Muricy, o General empenhou-se em descrever suas viagens pelo interior do Estado e, em sua obra, relacionou 236 vocábulos dispostos em ordem alfabética contendo explicações de uso ou significado do dialeto falado no Extremo Oeste paranaense. 
As observações feitas pelo General Muricy são importantes como ponto de partida para os estudos lexicais no Estado, embora traga em seu conteúdo formas linguísticas já cristalizadas na fala rural de outras regiões brasileiras. Registros como arco-da-velha para arco-íris, mãe-de-ouro para estrela cadente ou pataca para rótula, para citar alguns, são frequentemente encontrados na linguagem rural brasileira. Mesmo assim, seu trabalho continua relevante, por permitir o conhecimento do vocabulário presente no Paraná quando ainda em fase de povoamento.

Em meados das décadas de 50 e de 60 do século XX, já dentro de uma realidade diferente da vivenciada por Muricy, com a introdução dos estudos linguísticos no currículo do ensino superior, vários estudiosos analisaram de forma sistematizada algumas especificidades dialetais registradas no Paraná. Como exemplos citam-se Amaral (apud AGUILERA, 1987) em seu estudo sobre a linguagem utilizada no litoral paranaense, que faz observações fonéticas como Iórie, para pronúncia de Jorge ou ingreia, para igreja; Toniolo (1967), também no campo da fonética, traçou um comparativo entre os falares de Santa Maria (RS) e Ponta Grossa (PR); Andretta (apud AGUILERA, 1987) estudou as semelhanças e as diferenças no nível fônico e lexical dos falares de Laranjeiras do Sul (PR) e Erexim (RS); e Wouk (1981), que estudou a fala dos descendentes ucranianos em Dorizon, comunidade do município de Mallet. Outros pesquisadores, apresentados a seguir, documentaram as variantes, em especial as lexicais, em diversos pontos do Estado.

Filipak (1976), em seu trabalho sobre a linguagem no Vale do Iguaçu, elenca 464 vocábulos pertencentes à fala rural paranaense e mais cinco palavras estrangeiras introduzidas na região, na intenção de trazer ao conhecimento dos estudiosos da língua portuguesa aspectos lexicais pouco difundidos e muitos ainda não dicionarizados. Alguns dos vocábulos elencados pelo autor são: bambo para indeciso, atrapalhado, frouxo; coivara para galhos, ramagens, tronco de árvores que não foram queimados totalmente nas roças; e destripar o mico para vomitar. 
Mercer (1979) apresenta em seu trabalho, além de um glossário sobre a pesca, um estudo das origens históricas da localidade e dos traços fonológicos, fonéticos, prosódicos e morfossintáticos da fala da região. Esses dados estão reunidos em sua tese de doutorado, Le lexique technique de pêcheurs de Guaraqueşaba (Brésil).

O estudo da fala paranaense empreendido por Janine e Julio Alvar (1979) registrou, em obra etnográfica, o vocabulário na região de Guaraqueçaba. Nessa pesquisa, Alvar e Alvar buscaram coletar, no vocabulário dos habitantes da localidade (1.390 lexias), elementos da fauna e da flora, nomes de instrumentos de trabalho, além de gravuras de objetos da cultura dos caiçaras.

A exemplo de todo país, cujas pesquisas dialetológicas feitas através do método geolinguístico estão a cada dia ganhando maior espaço nos meios acadêmicos, os estudos dialetais no Estado do Paraná também avançam. São vários os trabalhos que merecem destaque nesse cenário.

O primeiro deles é Aspectos lingüisticos da fala londrinense: esboço de um atlas lingüistico de Londrina - EALLO (AGUILERA, 1987). Foram selecionados 12 pontos linguísticos no município, nos quais foram entrevistados 27 informantes, com idade entre 30 e 60 anos, de ambos os sexos. O instrumento de coleta de dados foi adaptado, após inquéritos experimentais, do questionário preparado pelo Dr. Pedro Caruso para as pesquisas do ALESP - Atlas Lingüístico do Estado de São Paulo.

A pesquisa registrou, em cartas geográficas, a variedade linguística da localidade, documentando os fatos fônicos, o grau de influência dos grupos étnicos, além da influência indígena e as formas arcaicas presentes na fala dos londrinenses. Como ilustração, apresenta-se a carta 26 do EALLO em que são registradas as variantes para míope. 


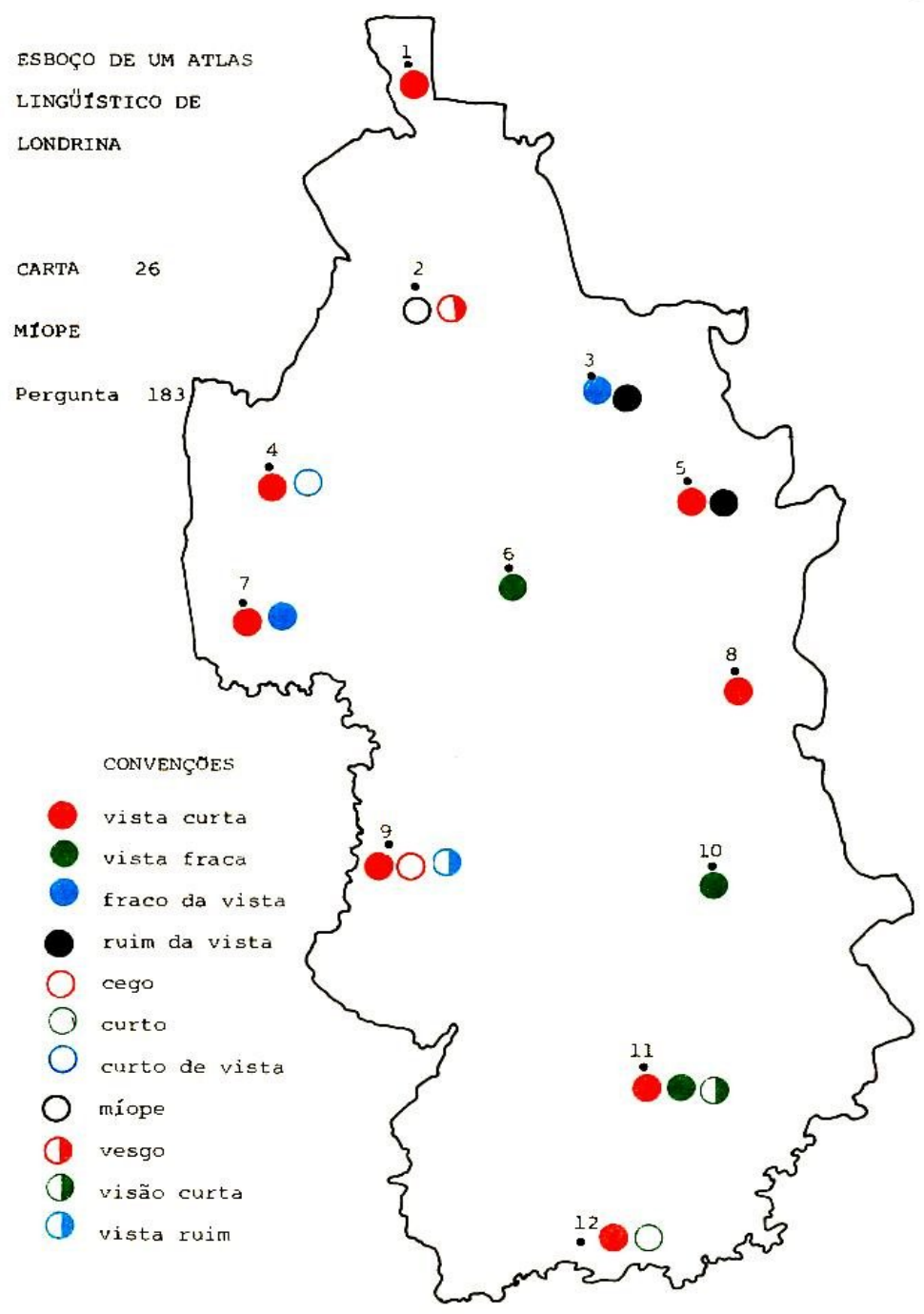

Figura 1 - Carta 26 do EALLO (AGUILERA, 1987) 
O estudo Áreas fonéticas do Paraná (MERCER, 1992) investigou nos dados coletados para o Atlas LingüísticoEtnográfico da Região Sul - ALERS as realizações fonéticas nas entrevistas constituintes do corpus paranaense. Logo no início do seu trabalho, Mercer (1992, p. 1), declara: "este trabalho propõese delimitar áreas fonéticas do Paraná e explicar suas configurações à luz da história da ocupação do Estado.”

Os dados são apresentados, em um segundo volume, em 48 cartas linguísticas e os resultados da pesquisa, no que tange à interpretação do corpus coletado, definiram como feixe de isoglossas: a) ditongação de /a/ tônico final seguido de /s/; b) ditongação de /u/ tônico final seguido de /s/; c) conservação de /e/ átono final; d) realização apical de /R/. Sobre estas realizações, Mercer (1992, p. 107-108), conclui

Pode-se dizer que, de forma esquemática, esse feixe de quatro linhas divide o Paraná em norte e sul e circunscreve, no sul, uma área a leste com ocorrência de ditongação de tônico final, pelas quais se liga ao norte. [...] Essa divisão no que chamaremos Área Norte e Área Sul - vem indicada no ALP (sic) de Vanderci AGUILERA. ${ }^{[4]}$

Para fins de exemplificação, visualizamos a carta 41 (na página seguinte, por motivo de espaço), que mostra a realização de /o/ pretônico seguido de sílaba pretônica com /i/.

\subsection{Os estudos dialetais na Universidade Estadual de Londrina - UEL}

A publicação do Atlas Lingüístico do Paraná - ALPR abriu caminhos para novos trabalhos no campo da Dialetologia despertando, em particular nos alunos da pós-graduação da Universidade Estadual de Londrina, o desejo de dar continuidade à pesquisa do léxico paranaense, sobretudo de base rural.

\footnotetext{
${ }^{4}$ Em referência a Aguilera (1990).
} 


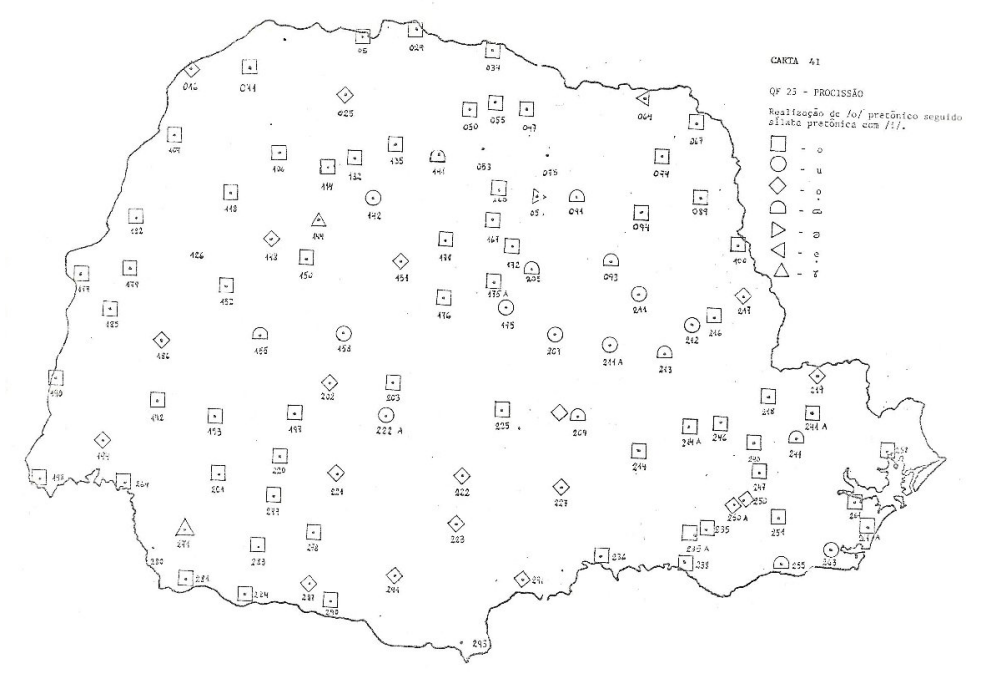

Figura 2 - Carta 41 de Áreas Fonéticas do Paraná (MERCER, 1992)

Um desses estudos foi o realizado por Lino (2000), em Aspectos Lingüisticos da fala de Cândido de Abreu: um estudo geossociolingüístico que busca analisar a fala cândido-abreuense, documentando a influência dos diferentes grupos étnicos responsáveis pela formação daquela região.

Município situado no centro do Estado, essencialmente agrícola, agregou imigrantes poloneses, ucranianos, franceses e alemães que conviveram com os nacionais que nessa região residiam. A cidade recebeu também imigrantes libaneses e holandeses, que influenciaram na linguagem falada pelos moradores da localidade.

Foram realizados 36 inquéritos em nove pontos linguísticos, onde foram entrevistados quatro informantes, de ambos os sexos, distribuídos em duas faixas etárias, de 18 a 35 anos e 45 a 70 anos. Além desses aspectos, para que a pesquisa atingisse seu objetivo, a autora estabeleceu a urgência de estarem representados no quadro 
de informantes as diversas etnias (alemães, italianos, ucranianos, poloneses, entre outros) formadoras do povo de Cândido de Abreu.

Para a constituição do corpus, a pesquisadora elegeu o instrumento de coleta dos dados do Projeto do Atlas Linguístico do Brasil-ALiB, contribuindo para esse projeto na medida em que os resultados serviram de parâmetro para a versão definitiva dos questionários do $A L i B$.

Como resultados obtiveram-se trinta cartas lexicais mistas com a variedade lexical e sete isolexicais elaboradas a partir de cartas anteriores. Lino (2000, p. 249) discute a influência da variável sexo e conclui que "os homens dominam um acervo lexical mais numeroso e que as diferenças lingüísticas entre os dois sexos estão profundamente relacionadas com suas experiências de vida familiar, econômica ou social". Segundo a autora, essas afirmações podem ser verificadas nas cartas sobre as designações para a parte alta do pescoço do homem na qual os homens forneceram um número maior de variantes $(77 \%)$ em relação às variantes coletadas entre as mulheres (33\%) e sobre as designações para a roupa que o homem usa debaixo da calça em que houve maior produtividade nas respostas masculinas $(60 \%)$ em relação às das mulheres $(40 \%) .^{5}$

Para a discussão sobre as etnias e suas influências da linguagem de Cândido de Abreu, a autora conclui que se pode notar um processo de aculturação em diversos campos: social, religioso, cultural e linguístico. No âmbito do léxico, a pesquisadora pouco encontrou variantes que tivessem origem polonesa, ucraniana ou alemã. Ela exemplifica com a resposta à questão 64 (que é que se abre com o machado, o facão, a foice para passar por um mato fechado) em que o informante respondeu rapindar e que ele próprio definiu como tipo de capoeira, mato fechado.

Lino (2000, p. 253) encerra afirmando que

\footnotetext{
${ }^{5}$ Observa-se que ambos os itens lexicais pesquisados fazem parte do universo masculino.
} 
... as três etnias, polonesa, ucraniana e alemã, sem dúvida povoaram e deram vida ao município. Aprenderam o nosso léxico, emprestaram-nos expressões lingüísticas, mas a língua nativa foi mais forte e dominou as demais. A grande influência estrangeira na fala de Cândido de Abreu, acreditamos, dá-se no nível fonético, tema para futuros trabalhos dialetológicos.

A carta 04, moinha, é apresentada como exemplo desse estudo em que se registram as variantes palha (com $48,4 \%$ das ocorrências), pó $(32,2 \%)$, moinha $(12,9 \%)$ e sujeira $(6,5 \%)$, carta esta que, por motivo de espaço, encontra-se na próxima página.

No Glossário da Fala Rural Paranaense (RODRIGUES, 2000), um dos objetivos é apresentar um rol da fala popular rural do Paraná com base na reunião e comparação de obras sobre o léxico desse Estado. Para tanto, a autora selecionou quatro estudos de um universo de nove obras de maior vulto, que privilegiam o Norte, o Sudeste, a região central e o litoral paranaense. Fazem parte também desse estudo as informações contidas no Atlas Lingüístico do Paraná (AGUILERA, 1994), que reflete a fala rural popular de todas as regiões do Estado. ${ }^{6}$

A reunião dessas obras gerou, após análises e recortes, 511 lexias, com as quais foi organizado o glossário. Os trabalhos selecionados descrevem a fala de vários pontos do Estado e terminam por complementar-se, revelando o conhecimento do homem do campo. No caso do Glossário da Fala Popular Rural a principal contribuição se dá por permitir a comparação de dados a partir de trabalhos diversos, o que facilita o alcance de uma visão conjunta.

\footnotetext{
'Algumas vozes regionais do Paraná do Extremo Oeste (MURICI, 1938); Vocabulário de Tibagi (TONIOLO, 1981); Aspecto lingüistico da fala londrinense: esboço de um Atlas Lingüístico de Londrina - EALLO (AGUILERA, 1987); Atlas Lingüístico do Paraná - ALPR (AGUILERA, 1994).
} 


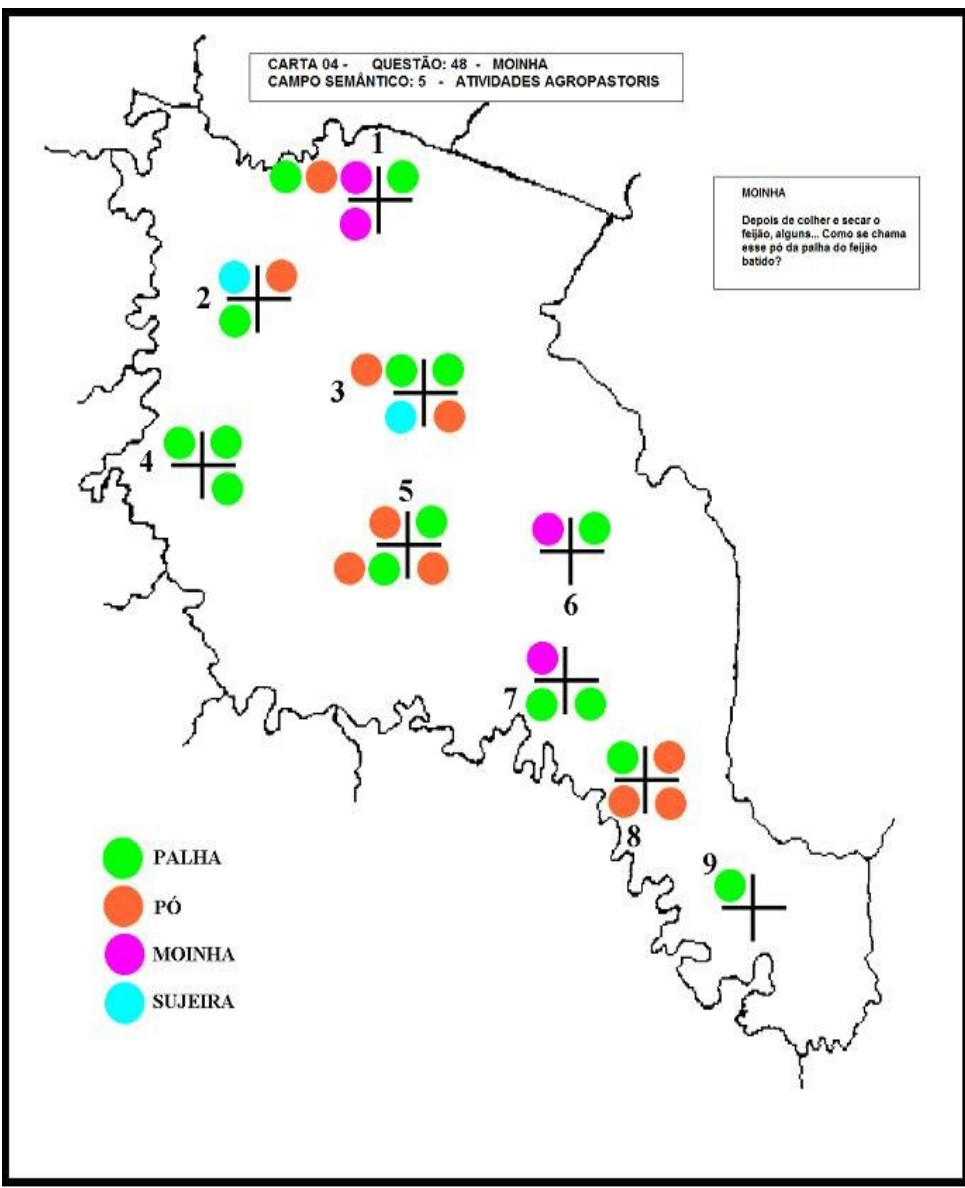

Figura 3 - Carta 04 de Aspectos Lingüísticos da fala de Cândido de Abreu: um estudo geossociolingïistico (LINO, 2000)

Altino (2001), em Pelos caminhos da Geolingüistica paranaense: um estudo do léxico popular de Adrianópolis, focaliza o estudo da fala popular em Adrianópolis, com o objetivo de analisar e registrar em cartas linguísticas os dados lexicais da língua oral, coletados por meio de questionário estruturado contemplando parte do acervo semântico-lexical de falantes de duas gerações e de ambos 
os sexos com o mesmo grau de escolaridade. Esse corpus serviu como um dos elementos da comparação de dados para verificar as mudanças em tempo aparente. O tempo real dado pelos registros constantes das cartas comuns com o ALPR (AGUILERA, 1994a), embora num espaço cronológico relativamente pequeno, ofereceu pistas de como se processam as mudanças e/ou permanência da língua falada numa comunidade com aquele perfil.

Município situado no nordeste do Estado, teve, na década de 70, época de exploração das minas de chumbo, ouro e prata, uma população estimada em 11 mil habitantes, na sua maioria imigrantes. Pelo Censo de 2000, Adrianópolis contava com pouco mais da metade daquele número de habitantes, com uma população formada em sua maioria por adultos com pouca escolaridade. Outro fator relevante para a escolha desta localidade é seu considerável isolamento, tanto geográfico - localidade cercada pela Serra do Mar e por rios da região - quanto social, que podem indicar um possível conservadorismo no que diz respeito aos hábitos linguísticos.

Foram entrevistados 24 informantes de ambos os sexos, com mínima ou nula escolaridade e de duas faixas etárias (de 20 a 45 e acima de 55 anos), em seis pontos linguísticos. Para esta pesquisa, foi utilizado como instrumento o questionário do $A L i B$, pois, segundo Altino (2001), sua estrutura abrange as mais diversas áreas semânticas (15 ao todo), satisfazendo aos objetivos do trabalho. Foram selecionadas 105 questões dentre as 207 propostas pelo Questionário Semântico-Lexical do $A L i B$.

Como resultado da pesquisa, foram elaboradas 109 cartas linguísticas, cuja análise foi sistematizada em duas seções: a primeira parte consta da análise das cartas comuns com o ALPR (AGUILERA, 1994a), subdividido nos campos semânticos estabelecidos pelo instrumento de coleta; a segunda parte trata da análise das cartas não coincidentes com o ALPR. Foram pontos de discussão: o polimorfismo, a manutenção da fala popular arcaica, o fator diatópico e as marcas regionais.

A análise dos resultados mostra que as mudanças linguísticas, embora de maneira lenta, vêm acontecendo devido à necessidade 
de inovações na linguagem, como é o caso das brincadeiras infantis (como exemplo a carta 81, designações para esconde-esconde, como ocorrência mãe-cega) ou de adotar uma lexia que recubra melhor os conceitos, como nas cartas que versam sobre as designações para tangerina e para menino.

Quanto à variável faixa etária, os dados indicam que a maior proximidade dos jovens com outras culturas, por meio da televisão, do rádio ou do convívio com familiares e amigos, e que frequentam a escola, tenha desencadeado mudanças lexicais tais como o registrado na carta 47, em que os informantes jovens registraram micróbio para sanguessuga, e na carta 31 (designações para bolsa que se coloca no lombo do cavalo ou burro), em que a maioria dos informantes da primeira faixa etária respondeu bruaca, e os mais jovens registraram bolsa, mala, capa da cangalha, atualizando algumas formas genéricas e desprezando outras arcaicas.

Os dados permitem concluir que, apesar das mudanças lexicais se efetuarem de forma lenta - haja vista a correspondência de variantes nas cartas comuns com o ALPR (AGUILERA, 1994a), outras variantes parassinônimas indicam que a faixa etária é o fator determinante mais significativo para a diversidade do léxico na fala em Adrianópolis que o fator sexo. Observando-se as cartas linguísticas, verifica-se que a primeira faixa etária (mais velhos) forneceu um número maior de variantes para os conceitos solicitados $(52,5 \%)$, enquanto os da segunda faixa registraram menor produtividade $(47,5 \%)$.

O conservadorismo linguístico e a mudança lenta observada no acervo lexical da população adrianopolitense parecem estar ligados à predominância da população idosa, uma vez que os jovens deixam suas famílias para estudar ou trabalhar nos grandes centros urbanos.

O isolamento geográfico (serra, floresta e precariedade de meios de comunicação) e a constituição de uma população basicamente idosa são fatores que contribuem para que as alterações linguísticas inerentes à linguagem aconteçam de forma mais lenta e se mantenham na fala da comunidade as variantes coletadas e cartografadas há 10 anos, como mostra o exemplo da carta 28 nas designações para cangalha. 


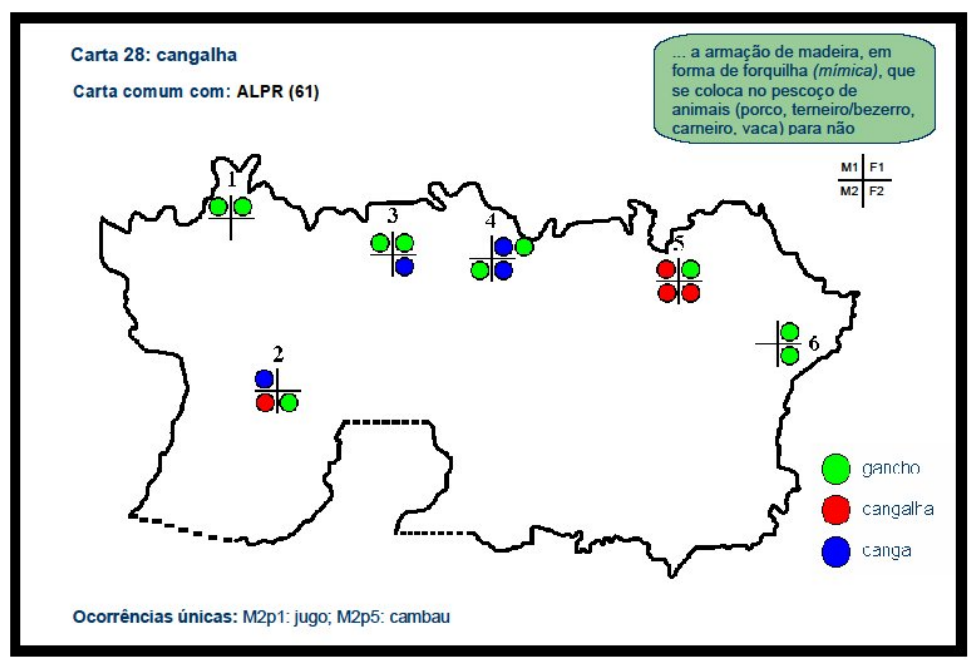

Figura 4 - Carta 28 do Pelos caminhos da Geolingüística paranaense: um estudo do léxico popular de Adrianópolis (ALTINO, 2001)

Toniolo (2002), Do presente ao passado: um olhar sobre o vocabulário de Tibagi, buscou estudar a variação lexical em tempo real e aparente, ocorridas em dois bairros rurais do município de Tibagi, região dos Campos Gerais do Paraná, em dois momentos, 1975 e 2001.

$\mathrm{O}$ autor desse estudo analisou o universo lexical tibagiense, valendo-se dos dados já recolhidos em 1975 na mesma cidade. Desta forma, efetuou-se um estudo em tempo real, voltando às localidades visitadas no ano de 75 e, em tempo aparente, coletando novos dados. Foram entrevistados 14 informantes, divididos entre os dois sexos e distribuídos entre três faixas etárias (de 18 a 30, 50 a 65 e acima de 75 anos) em dois pontos linguísticos.

Como instrumento de coleta de dados, retomou-se o questionário utilizado para a pesquisa em 1975, realizando algumas adaptações e acrescentando novas questões. Segundo o autor, a reformulação utilizou o questionário elaborado pelo $A L i B$ por representar a "decantação de numerosas pesquisas de natureza geolinguística, tendo sido revisado e aperfeiçoado em diferentes eventos" (TONIOLO, 2002, p. 33). 
Como conclusões de pesquisa, o autor reafirma a efetiva arcaização das lexias que denominam referentes em desuso. É o que apontam os exemplos: i) nas denominações para objetos de couro, com tampa, para levar farinha, no lombo do cavalo ou do burro, cita o autor que em relação à lexia bruaca, praticamente desaparecida com os tropeiros, alguns informantes da faixa intermediária conhecem a palavra, e poucos conhecem o objeto; ii) nas denominações para a unidade de medida de áreas, a lexia celamim é também pouco utilizada pelos falantes tibagiense. $\mathrm{O}$ trabalho de Toniolo aponta, ainda, outras lexias que estão em via de desaparecimento, tais como jojoca para soluço, e urupê para cogumelo.

Outra conclusão a que chegou o autor é que a influência da norma culta, vinda da escola e da mídia, revelou-se pouco significativa. Quanto à faixa etária, os adultos e mais idosos mostraram-se mais conservadores e menos propensos às inovações. As lexias consideradas novas pelo autor foram registradas nas falas dos informantes jovens e, provavelmente, "resultem da adoção de lexias provenientes de outras regiões, trazidas pelas correntes migratórias, ou pela própria mídia" (TONIOLO, 2002, p. 133).

Já o estudo Medicina caseira paranaense: um estudo geolingüistico, dissertação de mestrado de Souza (2005), realizado sobre os dados coletados para o corpus do $A L P R$, cartografou sete questões inéditas do subcampo semântico plantas medicinais: 088 - erva-doce (semente para chá contra dor de barriga); 090 - erva-de-santamaria (erva contra 'bicha' das crianças); 093 - sabugueiro (chá para arrebentar sarampo); 098 - arruda (planta para espantar mauolhado); 099 - ipê (árvore de flores amarelas e roxas); 101 - rubim (planta para dar sorte); 102 - guiné (planta para dar sorte).

O estudo de Souza analisou as respostas dos informantes e buscou as denominações de algumas plantas medicinais dentro das várias regiões do Estado. $\mathrm{O}$ trabalho apresenta uma discussão dessas variantes no vocabulário das plantas medicinais e a interferência da língua e/ou cultura da sociedade na configuração do léxico.

A autora conclui seu estudo afirmando: 
As variações, os empréstimos não se constituem em questão meramente lingüística, mas refletem a influência cultural e demais características às quais esteve sujeita a região. Uma vez que o indivíduo se revela pela língua; por extensão ela também revela o subgrupo a que pertence esse indivíduo. Da mesma forma que há marcas específicas que caracterizam um estilo individual, há características grupais - sejam grupos regionais, sociais ou profissionais - passíveis de serem observadas. (SOUZA, 2005, p. 95)

Como ilustração, a carta 7, que registra as variantes para guiné.

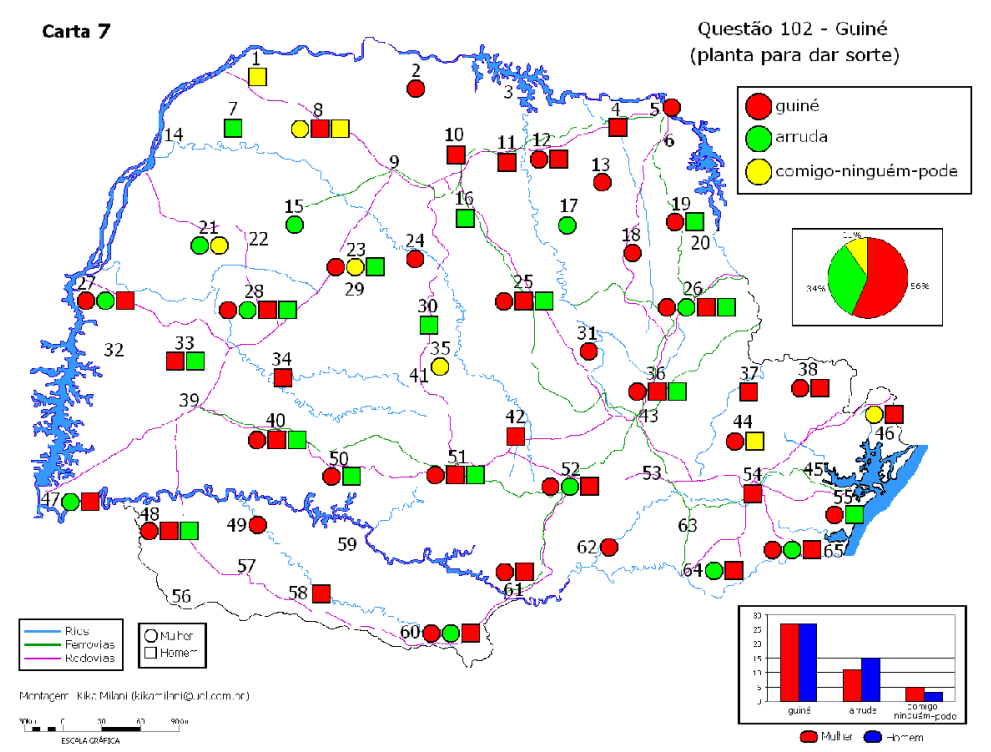

Figura 5 - Carta 7 de Medicina caseira paranaense: um estudo geolingüistico (SOUZA, 2005)

Dentre os trabalhos recentes realizado sobre a linguagem no Paraná está a tese de doutorado Em busca de uma história para o 
léxico ruralparanaense (RODRIGUES, 2007). A autora reuniu obras sobre a língua no Paraná, explicando a dinâmica vocabular das variantes no espaço geográfico com base nos dados linguísticos. Segundo Rodrigues (2007, p. 22), o estudo levanta a hipótese de haver no Estado, "áreas lexicais estreitamente ligadas ao povoamento [...] e que essas áreas são fruto da diferenciação cultural paranaense, nascida, por sua vez, da diversidade de indivíduos que aportaram no Estado".

O estudo comparativo/interpretativo de obras que tratam da fala paranaense, a seleção de 20 mapas do ALPR, ${ }^{7}$ a separação em áreas (no que tange à variação), a comparação dos dados analisados e a constituição de 90 novas cartas isoléxicas, compõem o perfil metodológico dessa tese. Foram reunidos dados linguísticos e extralinguísticos; estes últimos como suportes para a análise das áreas linguísticas sugeridas pela autora.

Como resultados da pesquisa foram delineadas três grandes áreas lexicais:

Em síntese, observamos que o Paraná possui três grandes áreas lexicais, que, como sabemos, interagem e estão mediadas por áreas de transição. O Norte do Estado possui suas próprias características léxicas, com um vocabulário oriundo em parte de mineiros, paulistas e nordestinos que, a partir do século $\mathrm{XX}$, desenvolveram a região. O Sul possui também características próprias e as variantes que nela ocorrem resultam em boa parte do contato com indivíduos da Região Sul, catarinenses e gaúchos que povoaram a região também a partir do século XX. No Centro Norte do Estado

\footnotetext{
${ }^{7}$ Cartas selecionadas: 01 - Terreno próprio para cultura do arroz; 02 Rio pequeno; 08 - Terreno úmido; 26 - Chuva de pedra; 27 - Trovão; 28 - Trovoada; 29 - Tempestade; 30 - Relâmpago; 31 - Raio; 38 Cogumelo; 39, 40, 41 - Cogumelo (outras designações); 46 - Banana dupla; 50 - Urubu; 51 - Gavião; 65 - Dentes molares; 66 - Dente do siso; 83 - Vagem do feijão; 87 - Papagaio.
} 
localiza-se uma área de transição na qual as variantes coocorrem. (RODRIGUES, 2007, p. 345)

A autora corrobora em seu trabalho a permanência de traços lexicais indígenas e de arcaísmos e a influência da norma padrão. Reafirma também que o ALPR cumpre seu papel, detectando e registrando os traços do vocabulário paranaense.

Para fins de exemplificação, apresenta-se a carta 1 na qual são traçadas as isoglossas para a variante banhado para terreno próprio da cultura de arro\%:

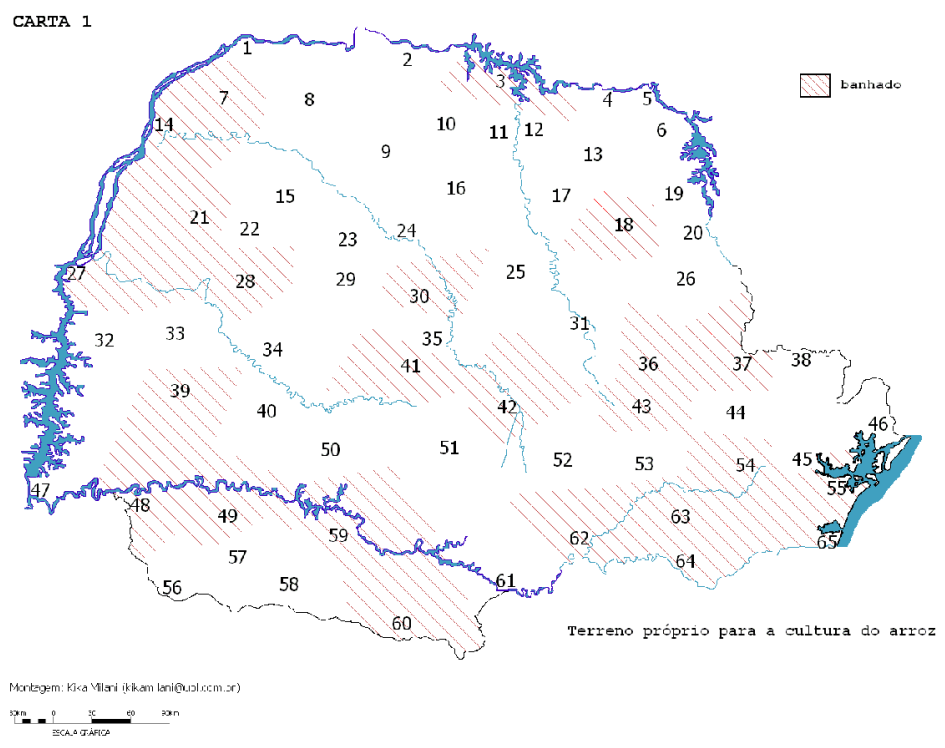

Figura 6 - Carta 1 de Em busca de uma história para o léxico rural paranaense (2007) 


\subsection{Atlas Linguístico do Paraná: dois momentos}

Os Atlas Lingüístico do Paraná - ALPR (AGUILERA, 1994a) e Atlas Lingüistico do Paraná - ALPR II (ALTINO, 2007) objetivaram cartografar as variantes lexicais e fonéticas. A metodologia do $A L P R$ foi norteada pela Dialetologia tradicional, postulada por Cunha e Silva Neto, no II Colóquio Internacional de Estudos LusoBrasileiros (1957) e por Nascentes (1958 e 1961) que, após algumas adaptações à realidade histórica e regional, apresentou-se da seguinte forma:

i) 65 localidades no Estado, seguindo inicialmente as sugestões postuladas por Nascentes $(1958$, p. 21$)$ e feitas as adaptações "levando-se em conta fatores etno-geo-históricos de cada um, aí incluindo a data de fundação" (AGUILERA, 1998, p. 108);

ii) o instrumento de pesquisa foi norteado pelo questionário do ALESP - Atlas Lingüistico do Estado do São Paulo (CARUSO, 1983), adotado quanto ao elenco dos conceitos e ao modo de formulação das questões. Após testagem inicial, o questionário sofreu alterações com acréscimo e supressão de algumas questões, para chegar ao questionário definitivo estruturado nos campos semânticos Terra e Homem;

iii) para os informantes (num total de 130) estabeleceramse critérios baseados em Nascentes (1958) e na Dialetologia tradicional (com Silva Neto, Coseriu, Alvar), aos quais foram acrescentados alguns dos conceitos que contemplam, além da dimensão diatópica, a diassexual (THUN, 1998). Em cada ponto linguístico, os informantes foram selecionados atendendo ao seguinte perfil: entre 30 e 60 anos, baixa ou nula escolaridade, a fim de obter dados mantidos na fala dos moradores sem a influência da escola; residentes na localidade, preferencialmente desde o nascimento ou ter vivido nela a maior parte de sua vida, se relacionar quase que integralmente com pessoas nascidas na localidade, ser ou ter sido agricultor, não ter viajado e, o homem, não ter feito o serviço militar; 
iv) foram realizadas entrevistas estruturadas com perguntas, em sua maioria, indiretas - método onomasiológico, ${ }^{8}$ que abordavam questões linguísticas e as implicações sóciohistóricas coocorrentes.

Para a cartografação dos dados do $A L P R$, inicialmente foram selecionados os vocábulos com o maior número de ocorrências. A partir das transcrições ortográficas fez-se "um levantamento de cerca de 250 vocábulos que apresentaram alguma variação, lexical ou fonética, significativa do ponto de vista dialetológico" (AGUILERA, 1990, p. 145). Seguiu-se a essa primeira seleção, a composição de um rol de 146 vocábulos-tema. Para o acervo lexical, levaram-se em conta as cartas dos atlas até então publicados - Bahia, Sergipe, Minas Gerais e Paraíba, "com o fim de expor os temas coincidentes nas cartas do ALPR." (AGUILERA, 1990, p. 146). Para as cartas fonéticas, foram levantadas as prováveis mudanças fonéticas que servissem de embasamento para o estudo dos sons produzidos com obstrução total à passagem de ar (contóides) e os produzidos sem a obstrução à passagem de ar (vocóides).

Como resultado, a autora apresenta 191 cartas geolinguísticas, que contemplam - ao lado das cartas necessárias para a localização e informações relevantes à pesquisa - cartas linguísticas sobre itens lexicais e aspectos fonéticos, acompanhadas de notas explicativas das variantes registradas; cartas de possíveis isoglossas que se podem traçar sobre a linguagem paranaense. A apresentação das cartas no ALPR (AGUILERA, 1994a) está assim sistematizada: i) cartas lexicais (1 a 92), foram selecionadas setenta

\footnotetext{
${ }^{8}$ Segundo Câmara Jr. (1981, p. 182), o método de pesquisa onomasiológico "consiste em reunir as expressões de que dispõe uma língua para traduzir determinada noção". No caso do questionário do ALPR, por exemplo, na questão 6, pergunta-se: "Como se chama aquela construção, feita de madeira ou cimento armado, que a gente usa para atravessar um rio de um lado para outro?", para chegar ao registro das variantes para 'ponte'.
} 
questões; ii) cartas fonéticas (93 a 162), correspondendo a cinquenta e seis questões; e iii) cartas isoglóssicas, ou sintáticas (163 a 191). As cartas lexicais e fonéticas foram apresentadas com as notas explicativas das variantes registradas.

Os documentos coletados por Aguilera (1985-1989), armazenados em forma de gravação e material escrito, têm servido de fonte de dados para diversas pesquisas científicas na UEL, desenvolvidas por alunos de graduação e de pós-graduação - lato e stricto sensu. Porém, boa parte desse corpus ainda não havia sido sistematizada e apresentada para o acesso à comunidade em geral.

Peça fundamental para a execução da tese de doutoramento de Altino (2007), os procedimentos metodológicos desta pesquisa, de cunho descritivo, consistiram no registro dos dados já coletados por Aguilera. A elaboração e a publicação do ALPR (AGUILERA, 1994a) contemplaram um recorte no corpus coletado. O ALPR II (ALTINO, 2007) retoma os dados registrados por Aguilera, cartografando os itens não contemplados no primeiro volume do atlas. Assim, o objeto da tese de Altino foram as questões inéditas, $54 \%$ do questionário aplicado.

Passados quase 20 anos da coleta de dados feita para a constituição do corpus para o $A L P R$, o estudo dos dados coletados anteriormente à consecução desta tese facultou possibilidades que o diferenciam da primeira edição do atlas. Os dados reunidos para este atlas, ainda sem publicação, foram sistematizados em um glossário que abrange os registros das cartas lexicais. Terminado o levantamento, chegou-se ao número de 1.036 registros, cujos significados foram apurados em duas obras: i) Dicionário Moraes Silva (1813); ii) Dicionário eletrônico Houaiss (2001). O glossário da tese de Aguilera (1990), em que constam “os termos cuja forma e/ou significados eram estranhos à linguagem urbana, ou pouco conhecidos neste contexto" (AGUILERA, 1990, p. 162) serviu para a verificação da existência da variante.

A exemplo do ALPR (AGUILERA, 1994a), as cartas apresentam informações semântico-lexicais, fonético-fonológicas e ocorrências únicas sobre as variantes registradas nos 65 pontos de estudo. Manteve-se a sistematização da cartografação: disposição 
dentro da carta, símbolos para designar os informantes (homens e mulheres) e, seguindo o modelo apresentado por Cardoso (2005) no segundo volume do $A L S$ II , ${ }^{9} \mathrm{com}$ a indicação dos maiores rios do Estado, o gráfico de frequências de respostas de homens e mulheres e a escala geográfica. $\mathrm{O}$ volume de cartas ficou, assim, sistematizado: cartas introdutórias, 125 cartas lexicais e 50 fonéticas. As cartas 18 e 197, retiradas do $A L P R$ e do ALPR II, respectivamente, mostram a continuidade na apresentação das variantes.

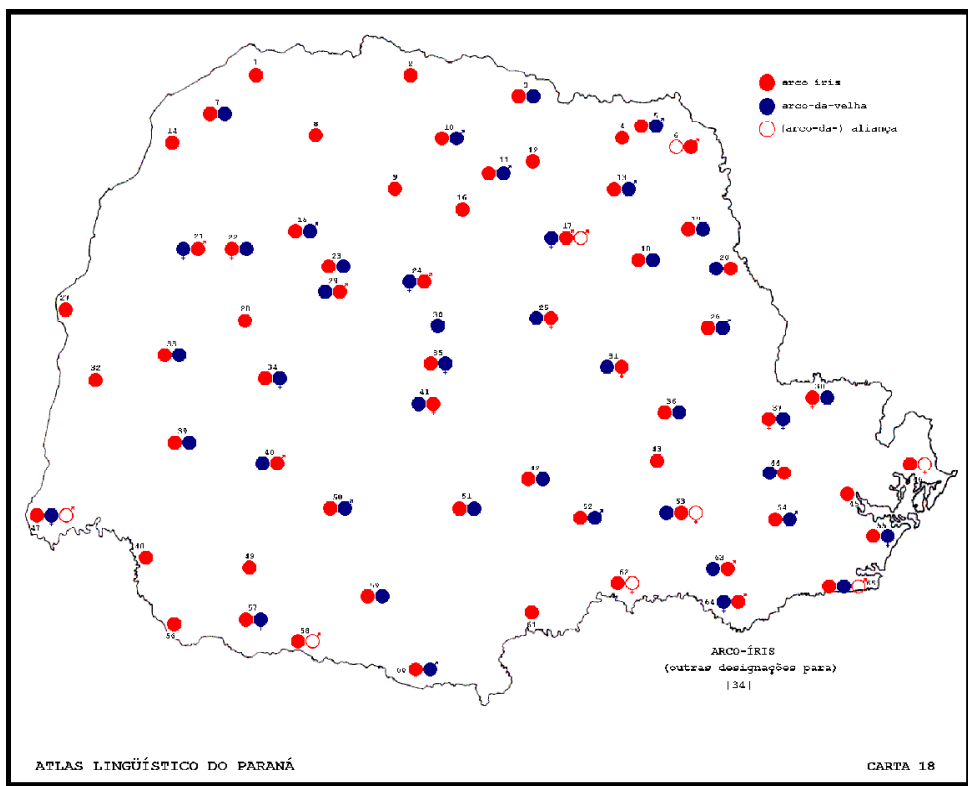

Figura 7 - Carta 18 do ALPR (AGUILERA, 1994a)

${ }^{9}$ O ALERS tem uma apresentação visual semelhante à do ALS II. 


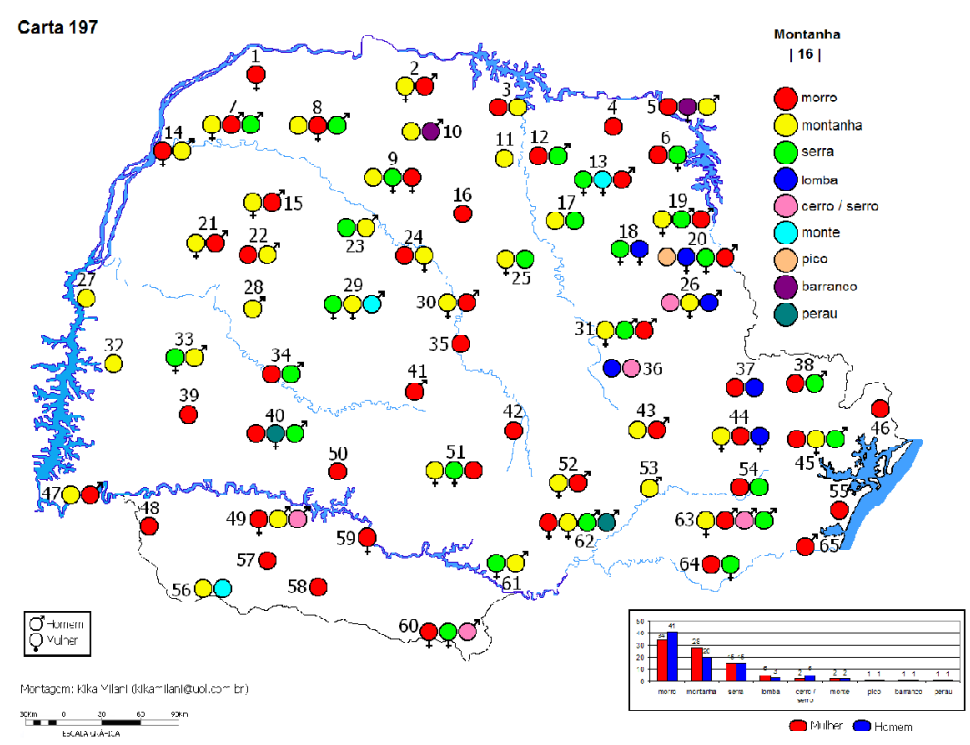

Figura 8 - Carta 197 do ALPR II (ALTINO, 2007)

O ALPR II teve como meta a cartografação dos dados inéditos coletados para o Atlas Lingüístico do Paraná (AGUILERA, 1994a), em um trabalho de cunho descritivo para a Dialetologia pelo método geolinguístico, dando continuidade aos estudos iniciados e possibilitando o acesso ao corpus coletado na ocasião. A cartografação é importante para a conservação e disseminação do acervo linguístico coletado. Por meio das cartas constantes do atlas, muitos estudiosos irão se servir dos dados para suas pesquisas, permitindo o entendimento dos usos linguísticos, dentro do contexto social da comunidade estudada.

Os dois atlas apontam, em linhas gerais, como provável motivação para a escolha lexical e fonética, a ocupação do Paraná com suas ondas povoadoras. Nos atlas verifica-se, por exemplo, a manutenção, no vocabulário ativo de falantes rurais, de unidades lexicais como burcão para nuvem escura (ALPR) e espigão para parte mais alta de um terreno (ALPR II), do português quinhentista, ou 
inconha para bananas grudadas (ALPR), juquiá para arapuca (ALPR II), vocábulos de base tupi. Como exemplo da pluralidade de designações, coocorrem variantes das normas culta e popular regional: barriga, útero, mãe-do-corpo e ventre, designações para útero (ALPR); ou pestana, cílios, capela dos olhos, pupila dos olhos, para cílios (ALPR II).

\section{Considerações finais: passos a seguir}

A importância dos estudos dialetológicos reafirma-se no elenco dos trabalhos desenvolvidos no Paraná, que contribuem para a preservação, compreensão e disseminação dos fatos linguísticos, sejam eles registrados tradicionalmente, isto é, apenas levando em conta o espaço geográfico, ou documentados pela dialetologia pluridimensional, que observa os diversos aspectos (diastrático, diageracional, diassexual...) influenciadores da linguagem.

Outro trabalho que vem sendo desenvolvido na UEL é a tese de doutoramento de Sanimar Busse, sob o título Atlas Linguístico-Etnográfico da Região Oeste do Paraná - ALERO. Pesquisas diversas estão, neste momento, tomando forma nas mãos de futuros dialetólogos que buscam em seus estudos, seja na Iniciação Científica ou nos bancos da pós-graduação, registrar e posteriormente analisar o falar paranaense. Um desafio maior que se coloca agora é a publicação do ALPR II. A tarefa de seleção dos conteúdos e a adequação textual pertinentes à editoração estão se iniciando e, em breve o Paraná, assim como Sergipe, terá dois atlas linguísticos publicados.

\section{Referências}

AGUILERA, Vanderci de Andrade. (Org.) A Geolingüística no Brasil: caminhos e perspectivas. Londrina: EDUEL, 1998.

Atlas lingüístico do Paraná - ALPR. Apresentação. Londrina: Eduel, 1996. 
Atlas lingüístico do Paraná - ALPR. Curitiba: Imprensa Oficial do Estado, 1994a.

. Atlas lingüístico do Paraná: algumas notas sobre a variação lexical. In: SEMINÁRIO DO CENTRO DE ESTUDOS LINGÜÍSTICOS E LITERÁRIOS DO PARANÁ, 8., Curitiba, 1994b. Anais... p. 1-16.

Atlas Lingüístico do Paraná. 1990. 426p. Tese (Doutorado em Letras) - Universidade Estadual Paulista Júlio de Mesquita Filho, Assis. 2 v.

Aspecto lingüístico da fala londrinense: esboço de um Atlas Linguístico de Londrina. 1987. 313p. Dissertação (Mestrado em Letras) - Universidade Estadual Paulista Júlio de Mesquita Filho, Assis. 2 v.

ALTINO, Fabiane Cristina. Atlas Lingüístico do Paraná - II. 2007. 223p. Tese (Doutorado em Estudos da Linguagem) Universidade Estadual de Londrina, Londrina. 2 v.

Pelos caminhos da geolingüística paranaense: um estudo do léxico popular de Adrianópolis. 2001. 218p. Dissertação (Mestrado em Letras) - Universidade Estadual de Londrina, Londrina. $2 \mathrm{v}$.

ALVAR, Manuel (Dir.) Manual de dialectología hispánica: el español de España. Barcelona: Editorial Ariel, 1996.

ALVAR, Júlio; ALVAR, Janine. Guaraqueçaba, mar e mato. Curitiba: UFPR, 1979.

.; __ Notas dialetológicas sobre Guaraqueçaba. Estudos Brasileiros, v. 2, p. 35-64, jun. 1977.

AMARAL, Amadeu. O dialeto caipira. 2. ed. São Paulo: HUICITEC/Secretaria da Cultura, 1976.

ARAGÃO, Maria do Socorro S. de; MENEZES, Cleusa B. de. Atlas lingüístico da Paraíba - ALPB. Brasilia: Universidade Federal da Paraíba/CNPq, 1984. 2 v. 
CÂMARA JR, Joaquim Mattoso. Dicionário de lingüística e gramática. Petrópolis: Vozes, 1981.

CARDOSO, Suzana Alice Marcelino. Atlas lingüístico de Sergipe II. Salvador: EDUFBA, 2005.

. Atlas lingüístico de Sergipe II. 2002. Tese (Doutorado em Letras - Letras Vernáculas) - Universidade Federal do Rio de Janeiro, UFRJ. $2 \mathrm{v}$.

CARUSO, Pedro. Atlas lingüístico do Estado de São Paulo: questionário. Assis: Instituto de Letras, História e Psicologia/ UNESP; Prefeitura Municipal de Assis, 1983.

CHAMBERS, Jack K.; TRUDGILL, Peter. La Dialectología. Madrid: Visor Libros, 1994. p. 19-32.

FERREIRA, Carlota et al. Atlas lingüístico de Sergipe - ALS. Salvador: UFBA/FUNDESC, 1987.

FILIPACK, Francisco; SICURO, Nelson A. A Antologia do Vale do Iguaçu. União da Vitória: Fundação Faculdade Estadual de Filosofia, Ciências e Letras de União da Vitória, 1976.

HOUAISS, Antonio. Dicionário Eletrônico Houaiss da Língua Portuguesa. s/1: Objetiva, 2001.

Sugestões para uma política da língua. Rio de Janeiro: Ministério da Educação e Cultura; Instituto Nacional do Livro, 1960.

KOCH, Walter; KLASSMANN, Mário Silfredo; ALTENHOFEN, Cléo Vilson. Atlas lingüístico-etnográfico da região sul do Brasil - ALERS. Porto Alegre; Florianópolis; Curitiba: UFRGS; EdUFSC; Editora da UFPR, 2002.

LINO, Fádua Maria Moisés. Aspectos lingüísticos da fala de Cândido de Abreu: um estudo geossociolingüístico. 2000. 291p. Dissertação (Mestrado em Letras - Estudos da Linguagem) Universidade Estadual de Londrina, Londrina. 
MERCER, José Luiz da Veiga. Áreas fonéticas do Paraná. Tese (Admissão como Docente Titular) - Universidade Federal do Paraná, Curitiba, 1992.

Le lexique technique des pêcheurs de Guaraqueçaba (Brésil). Tese (Doutorado em Estudos Românicos) - Université de Toulouse II, Toulouse, 1979.

MORAES SILVA, António de. Diccionario da lingua portugueza. Lisboa: Typographia Lacérdina, 1813. (edição digitalizada)

MURICY, Andrade. Algumas vozes regionais do Paraná do Extremo Oeste. Rio de Janeiro: Primeiro Congresso da Língua Nacional Cantada, 1938.

NASCENTES, Antenor. Bases para a elaboração do Atlas Lingüístico do Brasil: Questionário. Rio de Janeiro: MEC/Casa de Rui Barbosa, 1961.

Bases para a elaboração do Atlas Lingüístico do Brasil. Rio de Janeiro: MEC/Casa de Rui Barbosa, 1958.

OLIVEIRA, Dercir P. de. (Org.) Atlas Lingüístico de Mato Grosso do Sul. Campo Grande: UFMS, 2007.

RAZKY, Abdelhak. Atlas lingüístico sonoro do Pará: uma nova perspectiva para a organização de corpus geolingüístico. In: AGUILERA, Vanderci de Andrade (Org.). A Geolingüística no Brasil: trilhas seguidas, caminhos a percorrer. Londrina: Eduel, 2005. p. 209-228.

RIBEIRO, José; ZÁGARI, Mário Roberto L.; PASSINI, José; GAIO, Antonio. Esboço de um Atlas Lingüístico de Minas Gerais - EALMG. Rio de Janeiro: Fundação Casa de Rui Barbosa/ Universidade Federal de Juiz de Fora, 1977. v. 1.

RODRIGUES, Rosa Evangelina de Santana Belli. Em busca de uma história para o léxico rural paranaense. 2007. 180p. Tese (Doutorado em Estudos da Linguagem) - Universidade Estadual de Londrina, Londrina. 
Para um glossário da fala popular rural paranaense. 2000. 180p. Dissertação (Mestrado em Letras - Estudos da Linguagem) - Universidade Estadual de Londrina, Londrina.

ROSSI, Nelson; FERREIRA, Carlota; ISENSEE, Dinah. Atlas prévio dos falares baianos - APFB. Rio de Janeiro: INL/MEC, 1963.

SAINT-HILAIRE, Auguste de. Viagem a Curitiba e Santa Catarina. São Paulo: Ed. da Universidade de São Paulo, 1978.

SILVA NETO, Serafim da. Guia para estudos dialectológicos. 2. ed. Belém: Conselho Nacional de Pesquisa/Instituto Nacional de Pesquisas da Amazônia, 1957.

SOUZA, Solange Staciaki de. Medicina caseira paranaense: um estudo geolingǘ́stico. 2005. 123p. Dissertação (Mestrado em Estudos da Linguagem) - Universidade Estadual de Londrina, Londrina.

THUN, Harold. Movilidad demográfica y dimensión topodinámica. Los montevideanos en Rivera. New Wege der Romanischen Geolinguistic: Akten des Symposiums zur Empirischen Dialektologie (Heidelberg/Mainz 21-24, 10.1991). Kiel: WestenseeVerl, 1998. p. 210-225.

TONIOLO, Ênio J. Do presente ao passado: um olhar sobre o vocabulário de Tibagi. 2002. 140p. Dissertação (Mestrado em Letras - Estudos da Linguagem) - Universidade Estadual de Londrina, Londrina.

.Vocabulário de Tibagi. Apucarana: Fundação Faculdade Estadual de Ciências Econômicas, 1981.

- A linguagem da depressão central gaúcha e a dos campos gerais. Minerva, v. 1, p. 95-96, 1967.

WOUK, Miguel. Estudo etnográfico-lingüístico da comunidade ucraniana de Dorizon. Curitiba: Projeto, 1981. p. 107-110. 